\title{
Review of the Soft First Story Irregularity Condition of Buildings for Seismic Design
}

\author{
Arturo Tena-Colunga*
}

Departamento de Materiales, Edificio 4P, Último Piso, Universidad Autónoma Metropolitana Azcapotzalco, Av. San Pablo \# 180, Col. Reynosa Tamaulipas, 02200 México, DF, Mexico

\begin{abstract}
The present study evaluates how the soft first story irregularity condition should be defined: (a) as a significant reduction of the lateral shear stiffness of all resisting frames within a given story, as established in the seismic provisions of Mexican building codes or, (b) as a substantial reduction of the lateral shear stiffness of one or more resisting frames within a given story, as proposed by the author. Both definitions are evaluated through nonlinear dynamic analyses of buildings systems with a suspected soft first story condition in order to discern which option is closer to define the soft fist story condition.
\end{abstract}

Keywords: Soft first story, Structural irregularity, Design of irregular buildings, Lateral shear stiffness.

\section{INTRODUCTION}

Major damaging earthquakes (for example, San Fernando, 1971 and Mexico, 1985) have shown the vulnerability of buildings with soft first story, as many of them were severely damaged or collapsed during these events. Nevertheless, buildings with soft first stories are popular among architects, because this structural system allows them to use the first story for vehicle parking and/or retail stores, etc.

Structural engineers in seismic regions of Mexico and worldwide often face the pressure of architects and owners to design buildings with soft first story, even though they know these buildings are seismically vulnerable to potential failure or collapse under seismic loading. Modern seismic codes (among them, Mexico's Federal District Code, MFDC) have some provisions intended to prevent undesirable responses for buildings with soft first story. However, these provisions are based upon a few number of analytical and experimental researches.

The soft first story condition is recognized as an undesirable condition of structural irregularity for seismic design worldwide. Since 1987, MFDC has included soft story as a condition of structural irregularity to account for design [1,2] and the recent 2004 version has defined as one of the two conditions of strong irregularity [3], as discussed in the following section. In the United States, the UBC code also included the soft story condition since $1988[1,4]$ as one of the recognized vertical structural irregularities to account for design, and most recent regulations such as ASCE7-05 [5] and IBC-06 [6] endorse also these recommendations. Many other building codes worldwide have followed the pioneer

*Address correspondence to this author at the Departamento de Materiales, Edificio 4P, Último Piso, Universidad Autónoma Metropolitana Azcapotzalco, Av. San Pablo \# 180, Col. Reynosa Tamaulipas, 02200 México, DF, Mexico; Tel: + (52-55) 5318-9460; Fax: + (52-55) 5318-9085;

E-mail: atc@correo.azc.uam.mx ing recommendations of MFDC and UBC codes in this regard.

It is worth noting that there are some differences between Mexican and United States seismic codes in the definition of a soft story irregularity and how to account it for design purposes.

As per ASCE7-05 [5], a stiffness-related soft story irregularity is defined to exist when there is a story in which the lateral stiffness is less than $70 \%$ of that in the story above or less than $80 \%$ of the average stiffness of the three stories above, whereas a stiffness-extreme soft story irregularity is defined when target reference values of the conditions mentioned above are respectively $60 \%$ and $70 \%$. For design purposes, there are some restrictions on the permitted analytical procedures to use, as well as for some seismic design categories.

As it will be described more precisely in the following section, according to current seismic norms of MFDC [3], an irregularity condition defined in terms of stiffness exist where there is a story in which the lateral stiffness or the strength is less than $67 \%$ of that in the story above and a stiffness-extreme soft story irregularity when the lateral stiffness or the strength of a story is less than $50 \%$ of that in the story above. For design purposes, these structures must be designed for higher forces but required to comply with the lateral story drift criteria specified for regular buildings.

Therefore, in Mexican Codes stiffness and strength are grouped together to define a soft story irregularity, whereas in seismic codes of the United States the soft story irregularity is defined in terms of lateral stiffnesses, and a weak story irregularity is defined independently in terms of lateral strength [4-6]. The design philosophy to account for the soft story condition in US codes also differs from Mexican codes.

The present study evaluates the provisions available in Mexican codes for buildings with soft first story. In particu- 
lar, the research evaluates how the soft first story irregularity condition should be defined: (a) as a significant reduction of the lateral shear stiffness of all resisting frames within a given story, as established in the seismic norms of Mexican codes or, (b) as a substantial reduction of the lateral shear stiffness of one or more resisting frames within a given story, as proposed by the author. Both definitions are evaluated through nonlinear dynamic analyses of buildings systems with a suspected soft first story condition in order to discern which option is closer to define the soft first story condition.

\section{GUIDELINES OF MEXICAN SEISMIC CODES FOR SOFT FIRST STORY}

The seismic provisions of Mexico's Federal District Code (MFDC) define eleven conditions of regularity that building structures must satisfy to be designed as regular buildings [1$3]$. If one or more of these eleven regularity conditions are not fulfilled, then, the building is classified as an irregular building. According to NTCS-95 [2], the reductive seismic force factor $\mathrm{Q}^{\prime}$ has to be reduced by $20 \%$ for the design of irregular buildings $\left(\mathrm{Q}_{\text {irregular }}^{\prime}=0.8 \mathrm{Q}^{\prime}\right.$ regular $)$, which must be designed for higher forces but still be checked to comply with the story lateral drift criteria specified for regular buildings, that is, lateral deformations obtained from the analyses must be multiplied by Q in both cases, as schematically illustrated in Fig. (1).

The regularity condition \# 10 is:

10. The lateral shear stiffness or strength of any story shall not exceed by more than 100 percent the shear stiffness or strength of the story below the one in consideration. Thus, in terms of the stiffness alone, this implies that $K_{i} / K_{i-1} \leq 2.0$.

The violation of the regularity condition \# 10 defines the soft story condition according to NTCS-95. Therefore, according to NTCS-95, any given building has a soft first story condition when the shear stiffness of the second story is at least twice as much the shear stiffness of the first story $\left(K_{2} \geq\right.$ $\left.2 K_{l}\right)$.

The new seismic provisions NTCS-2004 [3] of Mexico's Federal District Code address the soft story condition in terms of the regularity conditions, as follows:
10. The lateral shear stiffness of any story shall not exceed by more than 50 percent the shear stiffness or strength of the adjacent story below the one in consideration. Thus, in terms of the stiffness alone, $K_{i} / K_{i-1} \leq 1.5$. The top story is exempt from this requirement.

If condition 10 is not met, the building is classified as irregular; therefore, $Q_{\text {irregular }}^{\prime}=0.9 Q^{\prime}$ regular must be used for the design. If two or more regularity conditions are not satisfied (including condition 10$), Q^{\prime}$ irregular $=0.8 Q^{\prime}$ regular.

If the lateral shear stiffness or shear strength of any story exceed more than 100 percent the shear stiffness or strength of the adjacent story below the one in consideration $\left(K_{i} / K_{i-}\right.$ $\geq \geq 2.0$ or $V_{i} / V_{i-1} \geq 2.0$ ), the building must be classified as strongly irregular and use $Q^{\prime}$ strongly-irregular $=0.7 Q^{\prime}$ regular.

As it can be concluded, the violation of condition \# 10 of former NTCS-95 is penalized in NTCS-2004 in a more severe manner. The new reading of regularity condition \# 10 of NTCS-2004 apparently is based in recent studies conducted in Mexico [7, 8].

It is clear that for both NTCS-95 and NTCS-2004, the definition and computation of the lateral shear stiffness of any story $i\left(K_{i}\right)$ is crucial for evaluating the soft story condition. In order to decide whether the building should be designed as a regular structure or as an irregular structure, in the Mexican design practice, indicative estimates of $K_{i}$ are often done in the first stages of the design process (preliminary design). However, the computation of $K_{i}$ can substantially vary depending on the analytical tools that are used. It has been common practice that some engineers obtain indicative values of $K_{i}$ using simpler equivalent shear models (Fig. 2b) to decide if the building should be designed as irregular. On the other hand, some other engineers have preferred to use the results of 3D building models to compute $K_{i}$. One can arrive to very different conclusions regarding the evaluation of the soft story condition depending on the method used to obtain indicative values for $K_{i}$.

Story larger lateral shear stiffnesses are always obtained using a shear modeling (Fig. 2b) with respect to an equivalent flexural 2D model (Fig. 2c) or a flexural 3D model, as the reduction caused by columns and beams end rotations is neglected. In addition, in modeling shear response, beams

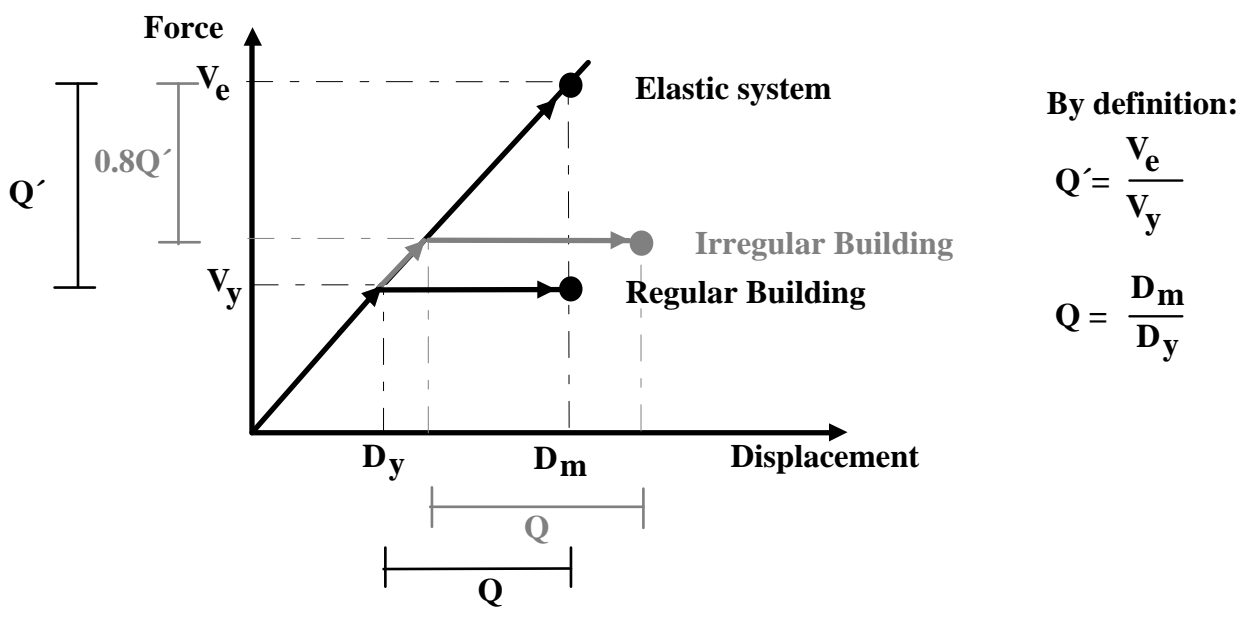

Fig. (1). Simplified scheme that roughly represents how Mexican seismic codes takes into account the reductions of seismic forces (using Q' factors) for inelastic deformations (in terms of the $\mathrm{Q}$ factors) for regular and irregular buildings. 
are often assumed to be axially rigid. These additional constraints make shear models (Fig. 2b) stiffer than equivalent flexural models (Fig. 2c). Besides, larger differences are usually calculated between the lateral shear stiffnesses of adjacent stories when using shear models instead of flexural models. Therefore, in some boundary cases and for the same building, a shear model would suggest that a soft story condition could trigger according to MFDC guidelines, but a flexural model would suggest that a soft-story condition could not be developed according to the same guidelines, so the building should not be designed as an irregular one [7]. This particularity will be illustrated in the following section with the building under study.

Tena-Colunga [7] also discussed whether the soft story irregularity condition should be defined: (a) as a substantial reduction of the lateral shear stiffness of all resisting frames in a given direction within a given story, as established in NTCS-95 and NTCS-2004 or, (b) as a substantial reduction of the lateral shear stiffness of one or more resisting frames within a given story, as proposed by the author.

A-priori, it is difficult to judge whether the definition of the soft story condition established by NTCS-95 or NTCS2004 is reasonable enough or not, as most of the previous studies taken into account to define the soft story condition in Mexican codes were done on isolated 2D frame models $[9,10]$. In the studies referenced, 2D shear frame models and 2D flexural frame models (one-bay or two-bays) were used to evaluate the soft story condition. Therefore, it has not been shown analytically that for having a soft story response in a given building, it is required that the lateral stiffness of all resisting frames in a given direction must be significantly reduced in order to have a substantial increment in the ductility demands of any given frame of that direction. On the other hand, the reverse has not been demonstrated either, that is, that significant increments in the drift and ductility demands of adjacent stories in a given direction of a building occurs when the lateral stiffness of one of its frames is significantly reduced in adjacent stories.

The study of twelve-story RC moment-resisting braced frame buildings with suspected soft first story condition that were designed according to NTCS-95 is presented in this paper. Both definitions for the soft first story condition (NTCS-95 and the one proposed by the author) are evaluated through the nonlinear dynamic analyses of these building systems in order to discern which option is closer to define the soft fist story condition. The design criteria for the buildings of reference and some of the most important results obtained from the nonlinear dynamic analyses will be briefly summarized in following sections.

\section{REFERENCE MODELS}

The reference model is named PSUAVE (Fig. 3), a twelve-story RC special moment-resisting braced frame building with built-in soft first story condition. The building is regular in plan, but it has discontinuity of the bracing in the first story of the perimeter braced frames (Fig. 3). The

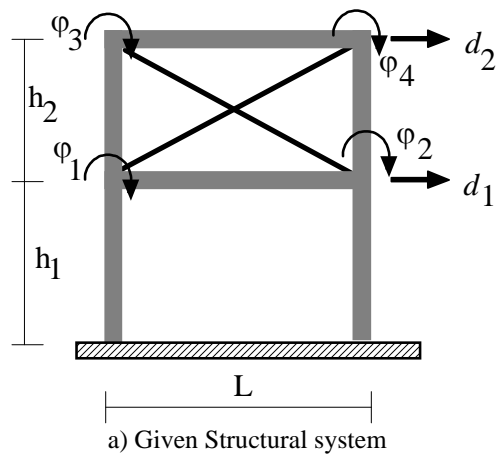

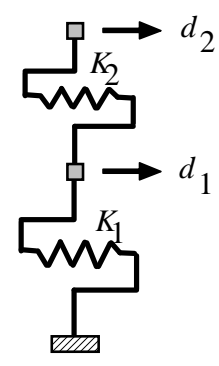

b) Shear modeling

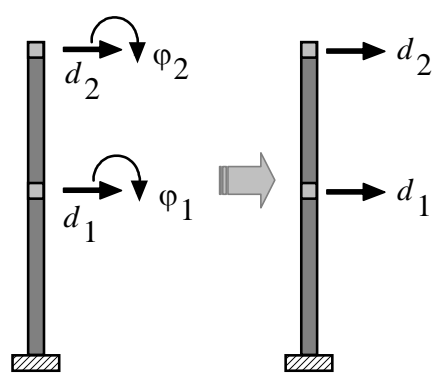

c) Equivalent flexural modeling

Fig. (2). Simplified models to estimate the story lateral shear stiffness.

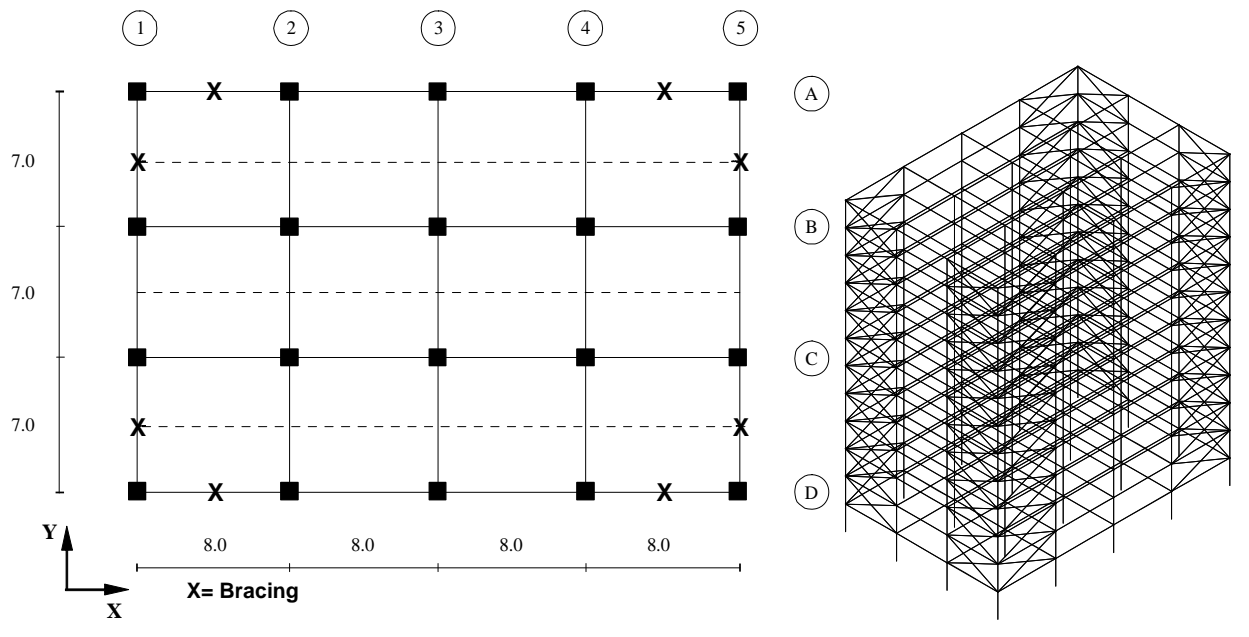

Fig. (3). Plan view and 3D ETABS model of building PSUAVE (dimensions in meters). 
general dimensions of the typical plan are shown in Fig. (3). The total height of the building is $39.6 \mathrm{~m}$, with a typical story height of $3.3 \mathrm{~m}$.

To illustrate the differences that can be obtained using a shear modeling or a flexural modeling to compute indicative values for the story lateral shear stiffnesses, the results obtained for building PSUAVE in the X direction (Fig. 3) using the structural sections and properties given in Table $\mathbf{1}$ are provided in Table 2 .

For the shear modeling, as often done, it was assumed that all beams are axially rigid and beams and columns end rotations are neglected (Fig. 2b). Therefore, it can be demonstrated that indicative values for the story lateral shear stiffness of braced frames can be estimated under such modeling as:

$K_{i}=\sum_{j=1}^{n c o l} \frac{12 E_{c^{\prime} l_{j}} I_{c o l_{j}}}{L_{c o l_{j}}^{3}}+\sum_{m=1}^{n b r} \frac{E_{b r_{m}} A_{b r_{m}}}{L_{b r_{m}}} \cos ^{2} \theta_{m}$

where $n \mathrm{col}$ is the total number of continuum columns in story $i, n b r$ is the number of braces in story $i ; E_{\mathrm{col}_{j}}, I_{\mathrm{col}_{j}}$ and $L_{\mathrm{col}_{j}}$ are the elastic modulus, the corresponding moment of inertia and the length of column $j$ of story $i$ for the direction of interest, respectively; and $E_{b r_{m}}, A_{b r_{m}}, L_{b r_{m}}$ and $\theta_{m}$ are the elastic modulus, axial area, length and angle of inclination with respect to a horizontal axis of brace $m$ of story $i$ for the direction of interest.

For the flexural modeling, $K_{i}$ was directly computed from story drifts obtained using inverted triangular lateral force distribution (first mode) in the direction of interest from a 3D ETABS analysis. The building was assumed to be fixed at its base.

From the results presented in Table $\mathbf{2}$ it is shown that for the same building, one can obtain very different results to assess the soft story conditions based on the method used to estimate $K_{i}$. This fact is relevant, as some engineers like to use simple calculations (for example, shear modeling) whereas other engineers rely heavily on results of detailed 3D models. Therefore, it would be convenient that building codes would specify in their commentaries which method of analysis should be used in order to define the story lateral stiffness of buildings when assessing the likeliness of a soft story irregularity condition.

Different ETABS models of building PSUAVE were designed for the lakebed zone of Mexico City (zone III) according to MFDC code [1] and its technical norms for reinforced concrete, steel members (bracing) and seismic design criteria [2]. Details on the seismic design according to the key specifications of NTCS-95 are provided in TenaColunga [8]. The models were designed using response spectrum analyses according to NTCS-95 and considering bidirectional effects for the ground motion, with the procedure outlined elsewhere [1].

Reductive seismic force factors $\mathrm{Q}^{\prime}$ regular $=\mathrm{Q}=4$ (regular) or $\mathrm{Q}^{\prime}$ irregular $^{\prime}=0.8 \mathrm{Q}^{\prime}{ }_{\text {regular }}=3.2$ (irregular) were used to evaluate the factor of safety involved in designing a building with a deliberate soft first story, as discussed in more detail elsewhere [8]. It is worth noting that $Q^{\prime}$ factors of Mexican seismic codes are conceptually equivalent to the R factors of the US seismic codes [1]. Then, four different models of building PSUAVE were designed to assess the validity of the definition of the soft story condition (in terms of regularity condition \# 10), computing the lateral shear stiffness as reported in Tables $\mathbf{3}$ and $\mathbf{4}$ depending if a shear or a flexural modeling was used:

a) Using $Q^{\prime}{ }_{\text {irregular }}=0.8 Q^{\prime}$ regular $=3.2$, considering that, in a given direction, when the lateral shear stiffness of one frame in the second story $\left(K_{2 m}\right)$ is at least $100 \%$ greater than the one of the first story $\left(K_{I m}\right)$, that is, when $K_{2 m} / K_{1 m} \geq 2.0$ is obtained with an indicative shear modeling (Table 3 ), a soft first story irregularity condition is introduced. This model was named M100Q32.

Table 1. Design Sections for PSUAVE Building to Illustrate Computation of Story Lateral Shear Stiffness, $K_{i}$

\begin{tabular}{|c|c|c|c|c|c|c|c|c|c|}
\hline \multirow[t]{2}{*}{ Stories } & \multicolumn{4}{|c|}{ Columns (Concrete) } & \multicolumn{5}{|c|}{ Bracing (Steel) } \\
\hline & Section $(\mathrm{cm})$ & ncol & $E_{c}(\mathrm{kN} / \mathrm{mm})$ & $L(\mathbf{c m})$ & Section (cm) & $n b r$ & $E_{s}(\mathrm{kN} / \mathrm{mm})$ & $L(\mathbf{c m})$ & $\theta$ \\
\hline $9-12$ & $60 \times 60$ & 20 & 217.2 & 330 & $35 \times 35 \times 1.91$ & 8 & 2000.3 & 865.4 & 22.42 \\
\hline $5-8$ & $70 \times 70$ & 20 & 217.2 & 330 & $35 \times 35 \times 2.22$ & 8 & 2000.3 & 865.4 & 22.42 \\
\hline $2-4$ & $80 \times 80$ & 20 & 217.2 & 330 & $35 \times 35 \times 2.54$ & 8 & 2000.3 & 865.4 & 22.42 \\
\hline 1 & $80 \times 80$ & 20 & 217.2 & 330 & - & - & - & - & - \\
\hline
\end{tabular}

Table 2. Evaluation of the Soft-Story Condition for PSUAVE Building, Depending if a Flexural or Shear Modeling is Used to Assess $K_{i}$

\begin{tabular}{|c|c|c|c|c|c|}
\hline \multicolumn{3}{|c|}{ Shear Modeling (Eqn. 1) } & \multicolumn{2}{c|}{ 3D ETABS Modeling } \\
\hline \hline$K_{2}(\mathrm{kN} / \mathrm{mm})$ & $K_{l}(\mathrm{kN} / \mathrm{mm})$ & $K_{2} / K_{l}$ & $K_{2}(\mathrm{kN} / \mathrm{mm})$ & $K_{l}(\mathrm{kN} / \mathrm{mm})$ & $K_{2} / K_{l}$ \\
\hline 10,163 & 4,950 & 2.05 & 3,674 & 2,877 & 1.28 \\
\hline
\end{tabular}


b) Using $\mathrm{Q}_{\text {regular }}=Q=4$, considering that, in a given direction, when the lateral shear stiffness of one frame in the second story $\left(\mathrm{K}_{2 \mathrm{~m}}\right)$ is at least $100 \%$ greater than the one of the first story $\left(K_{I m}\right)$, that is, when $K_{2 m} / K_{I m} \geq 2.0$, the structure should be considered regular according to NTCS-95 because $K_{2} / K_{I} \leq 2.0$ is computed using an indicative shear modeling (Table 3). This model was named M100Q4.

c) Using $\mathrm{Q}^{\prime}$ irregular $=0.8 \mathrm{Q}^{\prime}$ regular $=3.2$, considering that, in a given direction, when the lateral shear stiffness of all frames in the second story $\left(K_{2}\right)$ is at least $100 \%$ greater than the one of the first story $\left(K_{1}\right)$, that is, when $K_{2} / K_{1} \geq 2.0$ is obtained with an indicative shear modeling (Table 3 ), a soft first story irregularity condition is introduced, as specified by NTCS95. This model was named ED100Q32.

d) Using $Q^{\prime}{ }_{\text {regular }}=Q=4$, considering that, in a given direction, although the lateral shear stiffness of all frames in the second story $\left(K_{2}\right)$ is at least $100 \%$ greater than the one of the first story $\left(K_{l}\right)$ using an indicative shear modeling (Table 3 ), a smaller ratio $\left(K_{2} / K_{1}<2.0\right)$ is obtained with a $3 \mathrm{D}$ flexural modeling (Table 4) and, taking the flexural modeling as the most representative, then the structure should be considered regular according to NTCS-95. This model was named ED100Q4.

As it can be observed with the additional information provided in Tables 3 and 4, models M100Q4 and ED100Q32 were designed according to the definition of the soft story irregularity established by NTCS-95 when indicative stiffness values are obtained with the simplest shear modeling. Model M100Q32 was designed according to what the author believes it should be the definition of the soft story condition in Mexican codes, as discussed earlier. Model ED100Q4 represents a design where the structure was classified as regular as a consequence that the designer selected a $3 \mathrm{D}$ flexural modeling to compute the lateral shear stiffnesses, so the designer in fact computed that $K_{2} / K_{1}<2.0$ (Table 4).

The final relations obtained for the different models of PSUAVE building are reported in Table $\mathbf{3}$ when using the simpler shear modeling criteria given in Eqn. 1 and in Table 4 when using a 3D ETABS modeling. It can be observed from the results reported in Table 4 that all buildings should be designed as regular if the results of 3D flexural models are used, despite the fact that the building geometry suggests otherwise.

The details of the design (structural sections, reinforcement ratios, etc) are presented in Tena-Colunga [8]. Braces are of square box sections made with A-36 steel. The section of the braces from the second to fourth stories are $25 \times 25 \times 1.27 \mathrm{~cm}$ for models M100Q32 and M100Q4, and $35 \times 35 \times 2.54 \mathrm{~cm}$ for models ED100Q32 and ED100Q4. The typification of square cross sections for the columns of the first and second stories of all models are reported in Table $\mathbf{5}$ and the provided flexural and shear reinforcement are reported in Table 6.

The assessment of the design shear capacity for each story according to NTCS-95 is presented and discussed in detail elsewhere [7]. It was checked that the estimated shear capacity of the columns associated to a flexural failure according to a SMRF design would be smaller than the estimated shear capacity calculated from the provided transverse shear reinforcement and the own shear strength of the concrete section. Design buckling loads were used to estimate the contribution of the braces in the story shear.

Normalized design story shears obtained assuming a ductile flexural failure for the columns and the buckling loads for the braces are reported in Table 7 for the building

Table 3. Stiffness Ratios Obtained for the Building Models Under Study Using a Shear Modeling (Eq. 1)

\begin{tabular}{|c|c|c|c|c|c|c|c|}
\hline Model & $\boldsymbol{K}_{2} / \boldsymbol{K}_{I}$ & $K_{2 m} / K_{l m}$ & $\boldsymbol{K}_{2} / \boldsymbol{K}_{I}$ & $K_{2 m} / K_{l m}$ & NTCS-95 & NTCS-2004 & Designed as \\
\hline M100Q32 & 1.66 & 2.31 & 1.70 & 2.41 & No & Yes & Irregular \\
\hline M100Q4 & 1.66 & 2.31 & 1.70 & 2.41 & No & Yes & Regular \\
\hline ED100Q4 & 2.36 & 3.72 & 2.46 & 3.92 & Yes & Yes & Regular \\
\hline
\end{tabular}

Table 4. Stiffness Ratios Obtained for the Building Models Under Study Using a 3D ETABS Modeling

\begin{tabular}{|c|c|c|c|c|c|}
\hline \multirow[t]{2}{*}{ Model } & \multirow{2}{*}{$\begin{array}{c}\text { X Direction } \\
K_{2} / K_{I}\end{array}$} & \multirow{2}{*}{$\begin{array}{c}\text { Y Direction } \\
K_{2} / K_{I}\end{array}$} & \multicolumn{2}{|c|}{ Soft First Story Irregularity According to } & \multirow[t]{2}{*}{ Designed as } \\
\hline & & & NTCS-95 & NTCS-2004 & \\
\hline M100Q32 & 1.13 & 1.14 & No & No & Irregular \\
\hline M100Q4 & 1.13 & 1.14 & No & No & Regular \\
\hline ED100Q4 & 1.28 & 1.30 & No & No & Regular \\
\hline
\end{tabular}


models under study. If the shear strength ratios $V_{2 m} / V_{1 m}$ for the frames with the discontinuity of resisting elements could be considered to evaluate the soft-story condition due to strength (weak story), all models should be designed as irregular buildings as $V_{2 m} / V_{1 m}>2.0$ (Table 7). From the shear strength ratios $V_{2} / V_{l}$ reported in Table 7 it can be deducted that according to NTCS-95, models M100Q4 and M100Q32 do not have a soft-story irregularity due to strength $\left(V_{2} / V_{1}<2.0\right)$. It can also be deducted from the shear strength ratio $V_{2} / V_{l}=2.81>2.0$ reported in Table 7 that model ED100Q4 should be designed again to account for soft-story irregularity due to strength according to NTCS-95, despite the fact that the initial decision based upon a flexural stiff- ness modeling suggested otherwise (Table 4). However, it is also worth noting that if a practicing engineer estimated the design shear capacity of the columns from the provided transverse shear reinforcement and the own shear strength of the concrete section, then for ED100Q4 model the following values are obtained: $V_{2} / W=0.619, \quad V_{1} / W=0.314$ and $V_{2} / V_{l}=1.97<2.0$. Therefore, according to such assessment [7], ED100Q4 model can be designed as a regular structure according to NTCS-95, as it was finally done.

Peak story drift angles associated with the designs, all of them found in the first story as expected, are reported in Table 8. In most models, peak story drift angles were below

Table 5. Typification of the Columns for the First and Second Stories of the Models Under Study

\begin{tabular}{|c|c|c|c|c|c|c|c|c|c|c|}
\hline \multirow[t]{2}{*}{ Model } & \multicolumn{10}{|c|}{ Sections for Columns Intersecting Axes } \\
\hline & A1,D1 & A2,D2 & A3,D3 & A4,D4 & A5,D5 & B1,C1 & B2,C2 & B3,C3 & $\mathrm{B} 4, \mathrm{C} 4$ & B5,C5 \\
\hline M100Q32 & M-R3 & M-R3 & M-R4 & M-R4 & M-R3 & M-R2 & M-R4 & M-R4 & M-R4 & M-R2 \\
\hline M100Q4 & M-R1 & M-R1 & M-R1 & M-R1 & M-R1 & M-R1 & M-R4 & M-R4 & M-R4 & M-R1 \\
\hline ED100Q4 & E-R1 & E-R3 & E-R1 & E-R3 & E-R1 & E-R3 & E-R3 & E-R3 & E-R3 & E-R3 \\
\hline
\end{tabular}

Table 6. Section and Reinforcement for the Columns of the First and Second Stories of the Models Under Study

\begin{tabular}{|c|c|c|c|c|c|}
\hline Type & $\begin{array}{c}\text { Section } \\
\text { Dimensions (cm) }\end{array}$ & Bars & $\rho$ & Ends & Center \\
\hline M-R1 & $70 \times 70$ & $24 \# 8$ & 0.0248 & 6S\#3@9cm & 6S\#3@35cm \\
\hline M-R2 & $70 \times 70$ & $20 \# 8+4 \# 10$ & 0.0272 & 6S\#3@9 cm & 6S\#3@30 cm \\
\hline M-R4 & $70 \times 70$ & $24 \# 10$ & 0.0388 & 6S\#3@9 cm & 6S\#3@25 cm \\
\hline E-R1 & $75 \times 75$ & $16 \# 8$ & 0.0144 & 6s\#3@8cm & 6S\#3@35cm \\
\hline E-R2 & $75 \times 75$ & $20 \# 8$ & 0.0180 & $6 \mathrm{~S} \# 3 @ 8 \mathrm{~cm}$ & 6S\#3@35cm \\
\hline E-R3 & $75 \times 75$ & $24 \# 8$ & 0.0216 & 6s\#3@8cm & 6S\#3@35cm \\
\hline
\end{tabular}

Note: $\# 8$ bars $=$ bars one inch in diameter, $\# 3$ bars $=$ bars $3 / 8$ inch in diameter.

Table 7. Normalized Design Story Shear Forces Obtained for the Building Models Under Study

\begin{tabular}{|c|c|c|c|c|c|c|}
\hline \multirow{2}{*}{ Model } & \multicolumn{2}{|c|}{ Soft-Story Frame Concept (Frame A or Frame D) } & \multicolumn{2}{c|}{ All Frames Concept (Frames A, B, C and D) } \\
\cline { 2 - 7 } & $V_{2 m} / W$ & $V_{l m} / \boldsymbol{W}$ & $V_{2 m} / \boldsymbol{V}_{l m}$ & $V_{2} / W$ & $V_{I} / W$ \\
\hline \hline M100Q32 & 0.114 & 0.053 & 2.16 & 0.333 & 0.210 \\
\hline M100Q4 & 0.104 & 0.042 & 2.45 & 0.308 & 0.185 \\
\hline ED100Q32 & 0.212 & 0.049 & 4.29 & 0.526 & 0.201 \\
\hline ED100Q4 & 0.205 & 0.042 & 4.85 & 0.504 & 0.179 \\
\hline
\end{tabular}


the drift limit set by NTCS-95 [2] for buildings where non-structural elements are not properly separated from the structural system, $\Delta=0.006$ [1-3].

Table 8. Peak Design Drift Angle for the First Story

\begin{tabular}{|c|c|c|}
\hline \multirow{2}{*}{ Building Model } & \multicolumn{2}{|c|}{ Drift } \\
\cline { 2 - 3 } & X Direction & Y Direction \\
\hline \hline M100Q32 & 0.0065 & 0.0062 \\
\hline M100Q4 & 0.0052 & 0.0050 \\
\hline ED100Q32 & 0.0052 & 0.0048 \\
\hline ED100Q4 & 0.0042 & 0.0038 \\
\hline
\end{tabular}

The dynamic properties for the first three modes of each model are summarized in Table 9. Six modes were required for the design according to NTCS-95 [1,2].

\section{NONLINEAR DYNAMIC ANALYSES}

Nonlinear dynamic analyses were performed for all models using accelerograms SCT85-EW, TEX85-EW and TBOM85-NS recorded in Mexico City during the September
19, 1985 Michoacán earthquake $\left(\mathrm{M}_{\mathrm{s}}=8.1\right)$ in the lakebed zone (zone III). These accelerograms are associated to the design spectrum of NTCS-95. In fact, the plateau for the design spectrum of NTCS-87 and NTCS-95 was defined from SCT85-EW record, as reported elsewhere [11]. SCT85EW (Fig. 4) record is special, as it is the strongest acceleration time history recorded in the soft soils of Mexico City yet. Two-dimensional models that account for the interaction among frames in a given longitudinal direction (Fig. 5) were used for the dynamic analyses using DRAIN-2DX software. The rigid diaphragm action is modeled with link elements (rigid elastic axial rods) that transmit lateral loads from one frame to another without dissipating energy by any means (damping, hysteresis, etc.).

Because the frame models were assumed to be made of reinforced concrete, the following assumptions were taken for computing the nominal capacities of the beams and columns: (1) the concrete was modeled with the equivalent stress block established by the concrete norms of MFDC, (2) the "real" or actual distribution of the reinforcement steel according to the final design was considered and, (3) an elastic perfectly-plastic behavior of the reinforcement steel, as established by the concrete norms of MFDC, was assumed. For the steel bracing, an elastic-perfectly-plastic behavior in tension and elastic buckling in compression (taking into account the slenderness ratio $k L / r, k=1$ to compute the nominal buckling load) was assumed in the modeling. These assump-

Table 9. Dynamic Properties for the Different Models of PSUAVE Building

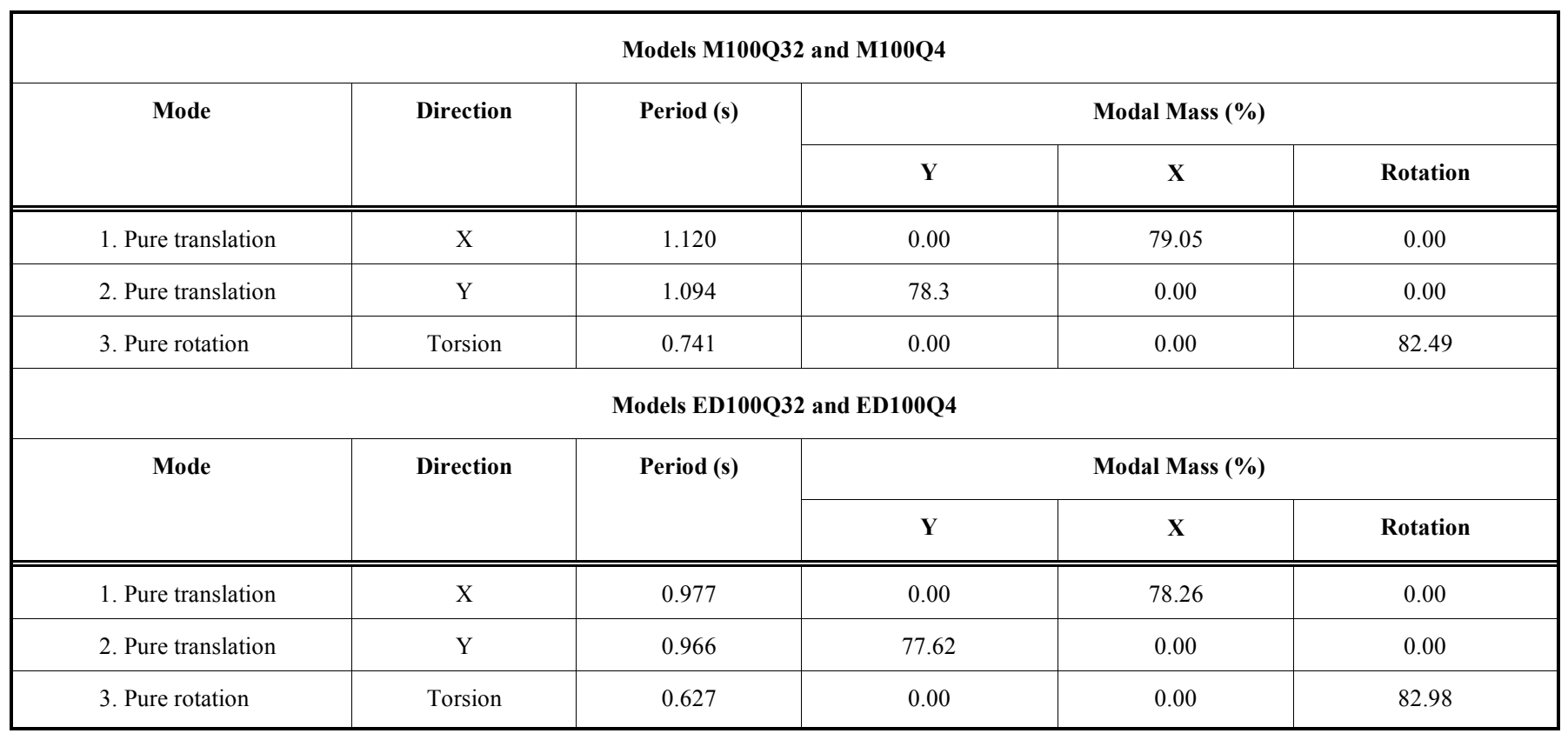
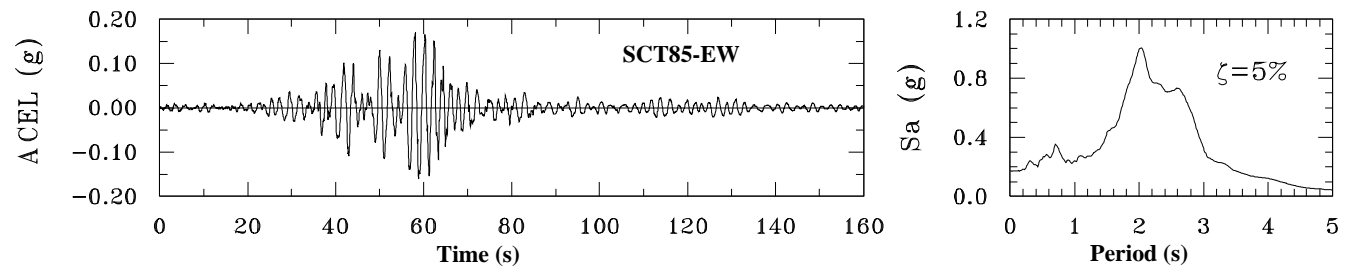

Fig. (4). SCT85-EW acceleration record. 
tions are consistent with the minimum overstrength associated to RCDF provisions. P- $\Delta$ effects were included in the nonlinear dynamic analyses.

Because of the symmetry of the models, only the computed response for frames A and B (Figs. 3 and 5) of all models in the $\mathrm{X}$ direction under the action of SCT85-EW acceleration record of the 1985 Michoacán earthquake will be briefly presented and discussed. The symmetric frames D and $\mathrm{C}$ have identical responses. Results for the representative frames in the Y direction are presented elsewhere [8].

Dynamic results processed from the analyses were envelopes for peak dynamic story drift angles $\left(\Delta=\Delta_{\mathrm{i}} / \mathrm{H}_{\mathrm{i}}\right)$, maximum dynamic story shear indexes $\left(\mathrm{V} / \mathrm{W}_{\mathrm{T}}\right)$, peak story ductility demands, (peak to peak) story effective shear stiffnesses and story hysteresis curves $\left(\mathrm{V} / \mathrm{W}_{\mathrm{T}}\right.$ vs $\left.\Delta\right)$, as well as yielding mapping for time-steps associated to peak dynamic re- sponses and the yielding mapping envelope for all time-steps (detect all elements that responded inelastically at least once).

Results of all models in the $\mathrm{X}$ direction are reported in Tables 10 to 12 and depicted in Figs. (6) to (9) (peak response envelopes), Figs. (10) to (13) (hysteresis curves) and Figs. (14) to (17) (yielding mapping envelopes). It is worth noting that in the response envelopes of Figs. (6) to (9), "NOMINAL" identifies the envelopes of peak responses of nonlinear dynamic analyses using nominal strength, "DESIGN" identifies the envelopes of a design according to the code, "RDF-a" identifies the drift limit $\Delta=0.006$ of MFDC when non-structural elements are not properly separated from the structural system and "RDF-b" identifies the drift limit $\Delta=0.012$ of MFDC when non-structural elements are properly separated from the structural system. In the hysteresis curves (Figs. 9 to 13) "GLOBAL" identifies the first story shear versus the global

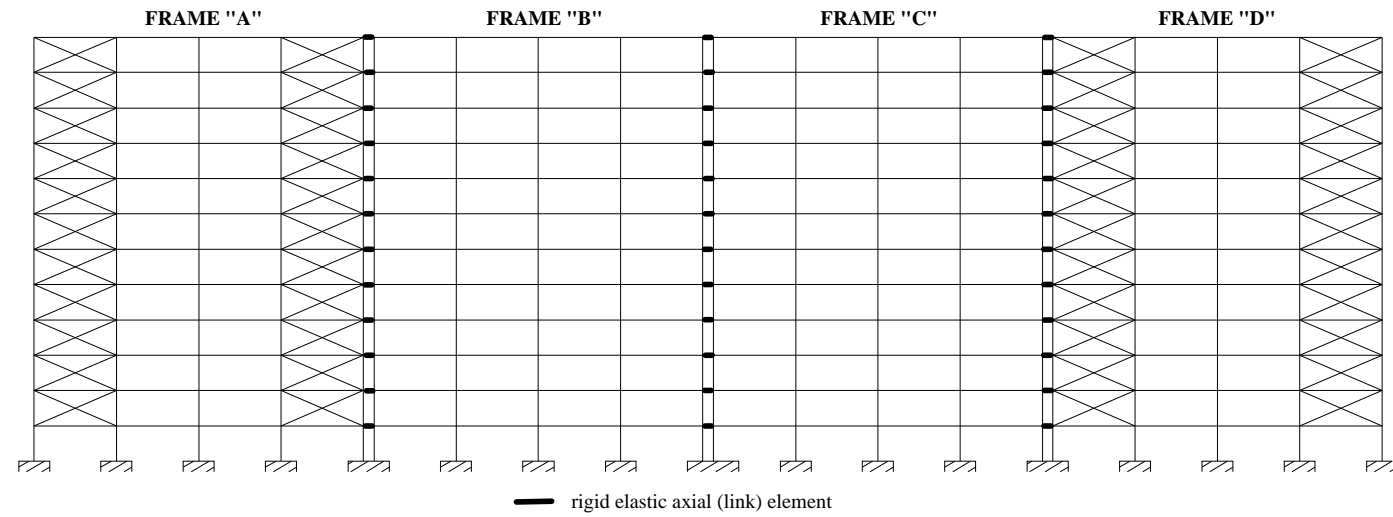

Fig. (5). Typical 2D model with interaction among frames in the $\mathrm{X}$ direction.

Table 10. Peak Responses from Dynamic Analysis, Perimeter Frames (A)

\begin{tabular}{|c|c|c|c|c|c|c|}
\hline Model & Drift, $\Delta$ & V/WT & Ductility Demand, $\mu$ & Drift, $\Delta$ & V/WT & Ductility Demand, $\mu$ \\
\hline M100Q32 & 0.0091 & 0.040 & 3.69 & 0.0047 & 0.096 & 1.54 \\
\hline M100Q4 & 0.0136 & 0.038 & 6.06 & 0.0068 & 0.098 & 2.19 \\
\hline ED100Q4 & 0.0092 & 0.036 & 5.66 & 0.0023 & 0.113 & 1.10 \\
\hline
\end{tabular}

Table 11. Peak Responses from Dynamic Analysis, Interior Frames (B)

\begin{tabular}{|c|c|c|c|c|c|c|}
\hline Model & Drift, $\Delta$ & V/WT & Ductility Demand, $\mu$ & Drift, $\Delta$ & V/WT & Ductility Demand, $\mu$ \\
\hline M100Q32 & 0.0091 & 0.062 & 2.47 & 0.0047 & 0.027 & 2.01 \\
\hline M100Q4 & 0.0136 & 0.067 & 3.45 & 0.0068 & 0.027 & 3.00 \\
\hline ED100Q4 & 0.0092 & 0.060 & 3.16 & 0.0023 & 0.030 & 1.60 \\
\hline
\end{tabular}


Table 12. Demanded Peak Normalized Story Shear Forces Obtained for the Building Models Under Study from Nonlinear Dynamic Analysis

\begin{tabular}{|c|c|c|c|c|c|c|}
\hline \multirow[t]{2}{*}{ Model } & \multicolumn{3}{|c|}{ Soft-Story Frame Concept (Frame A or Frame D) } & \multicolumn{3}{|c|}{ All Frames Concept (Frames A, B, C and D) } \\
\hline & $V_{2 m} / W$ & $V_{I m} / W$ & $V_{2 m} / V_{I m}$ & $\boldsymbol{V}_{2} / \boldsymbol{W}$ & $V_{l} / W$ & $V_{2} / V_{1}$ \\
\hline M100Q32 & 0.096 & 0.040 & 2.41 & 0.244 & 0.204 & 1.20 \\
\hline M100Q4 & 0.098 & 0.038 & 2.58 & 0.260 & 0.208 & 1.25 \\
\hline ED100Q4 & 0.113 & 0.036 & 3.17 & 0.286 & 0.191 & 1.49 \\
\hline
\end{tabular}

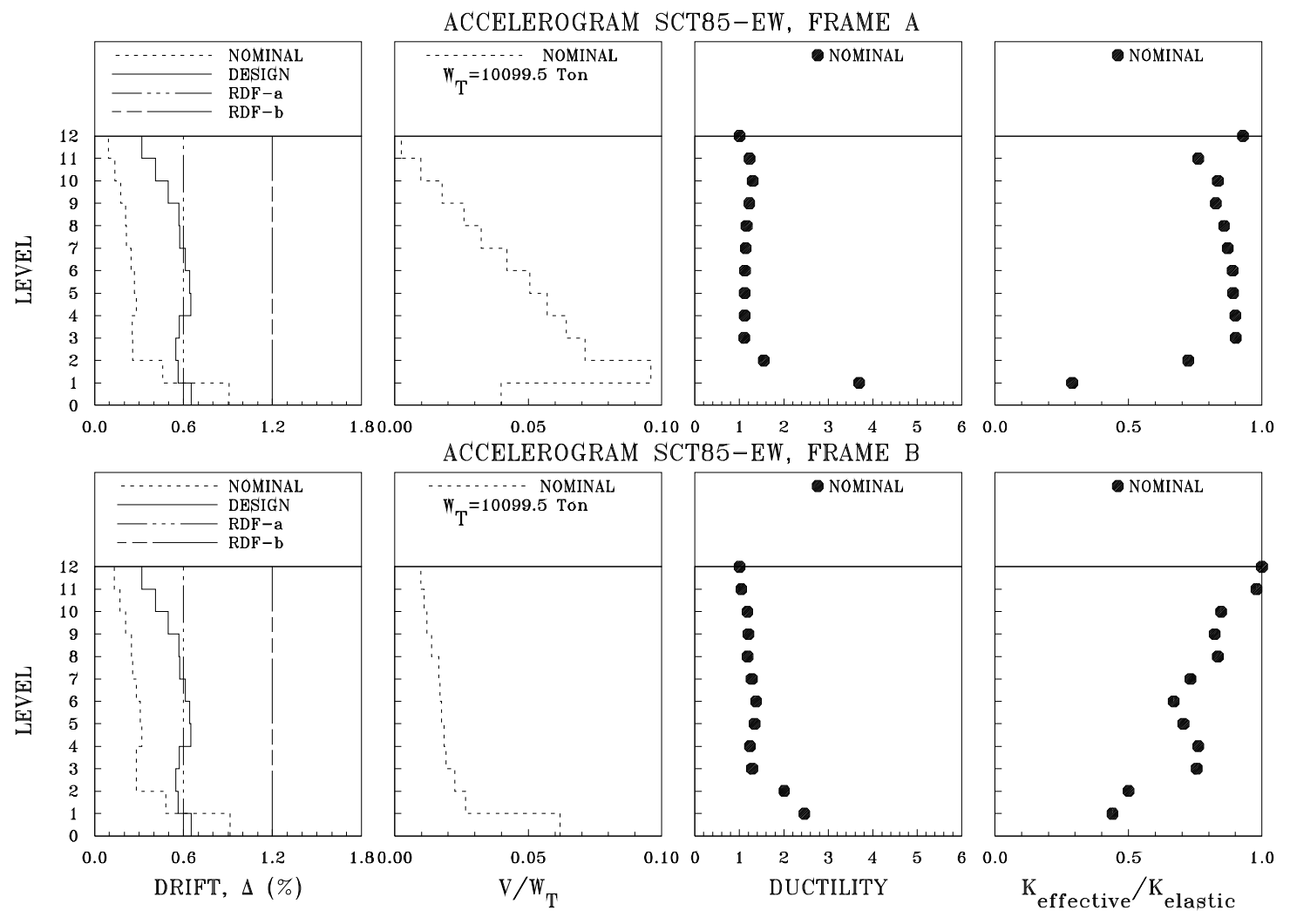

Fig. (6). Peak response envelopes for frames A and B of model M100Q32.

drift hysteresis curve, that is, base shear vs the drift between the roof and the base. It is also worth noting than in the yielding maps, the intensity scale for beams and columns was defined with respect to the peak plastic rotation $\theta=0.053 \mathrm{rad}$ obtained for the exterior base columns of frames A and D of M100Q4 model (Fig. 15). Similarly, the intensity scale for the axial "buckling" shortening for the braces was defined with respect to the peak shortening $\delta_{\text {buck }}=2.10 \mathrm{~cm}$ observed also in frames A and D of M100Q4 model (Fig. 15). Only axial shortening related to a buckling condition are identified (i.e., elastic shortening of braces is not plotted).

The following observations can be made from Figs. (6) to (17) and Tables 8 and $\mathbf{1 0}$ to 12:

(1) For all models, peak dynamic story drift angles of the first soft story surpass those computed for the design (Tables 8, 10 and 11), and they are associated with considerably higher ductility demands than the one experi- enced in the remaining stories, where an almost elastic response is observed for most models (Figs. 6 to 9).

(2) As observed from the yielding mapping envelopes (Figs. 14 to 17), these higher displacement and ductility demands are related to important yielding of the first story columns and beams of both perimeter and interior frames, although the condition is more severe for perimeter frames where the stiffness and strength discontinuity is set, particularly for the models that were designed as regular buildings (M100Q4 and ED100Q4 models, Figs. 15 and 17).

(3) As expected, a substantial strength reduction capacity in the first story of the perimeter frames (represented by frame A) is detected, compared to the one that it is developed in the second story (Table 12, Figs. 6 to 9), as a consequence of the discontinuity of the bracing in the first story (Fig. 5). 


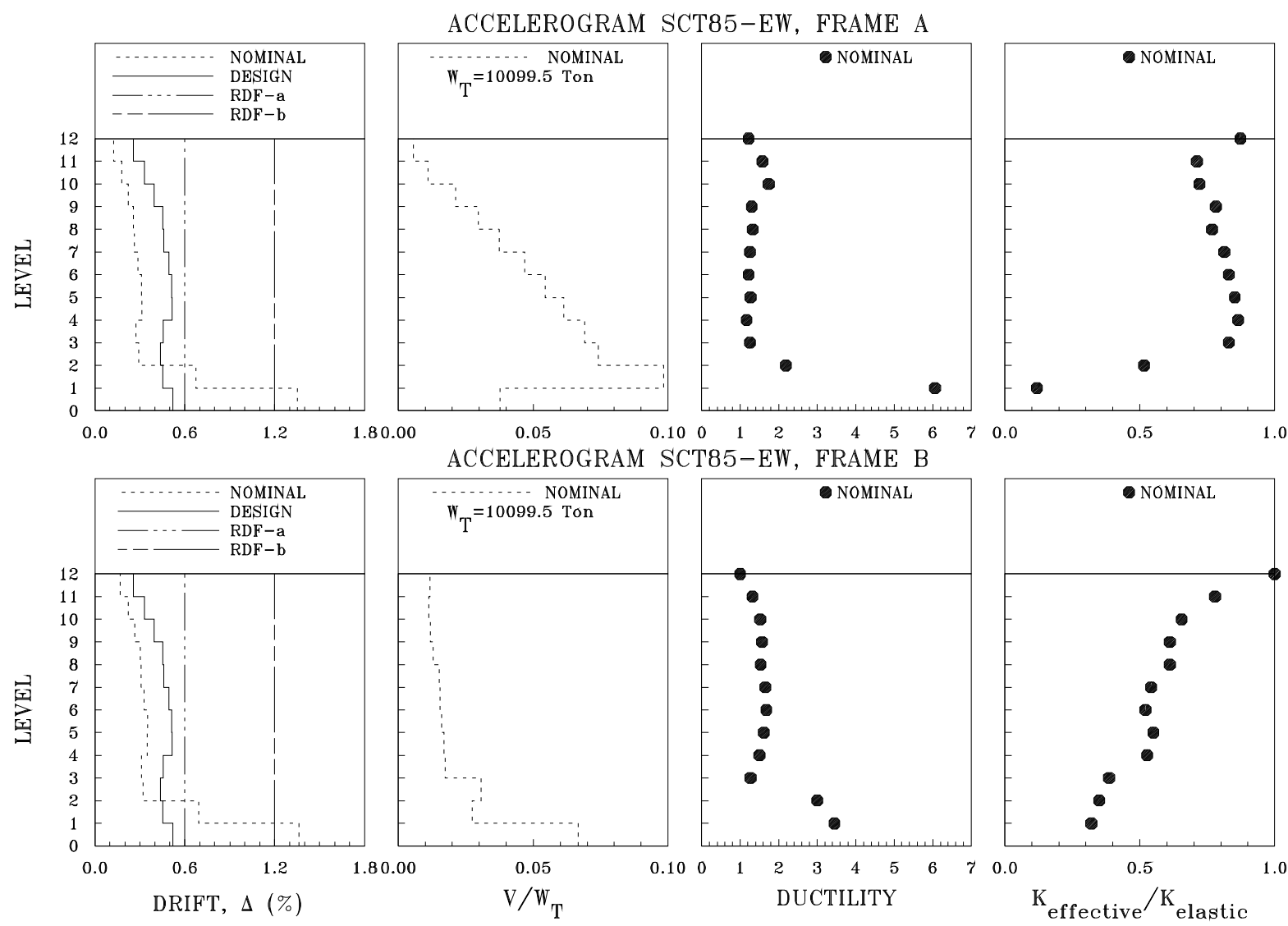

Fig. (7). Peak response envelopes for frames $\mathbf{A}$ and $\mathbf{B}$ of model M100Q4.
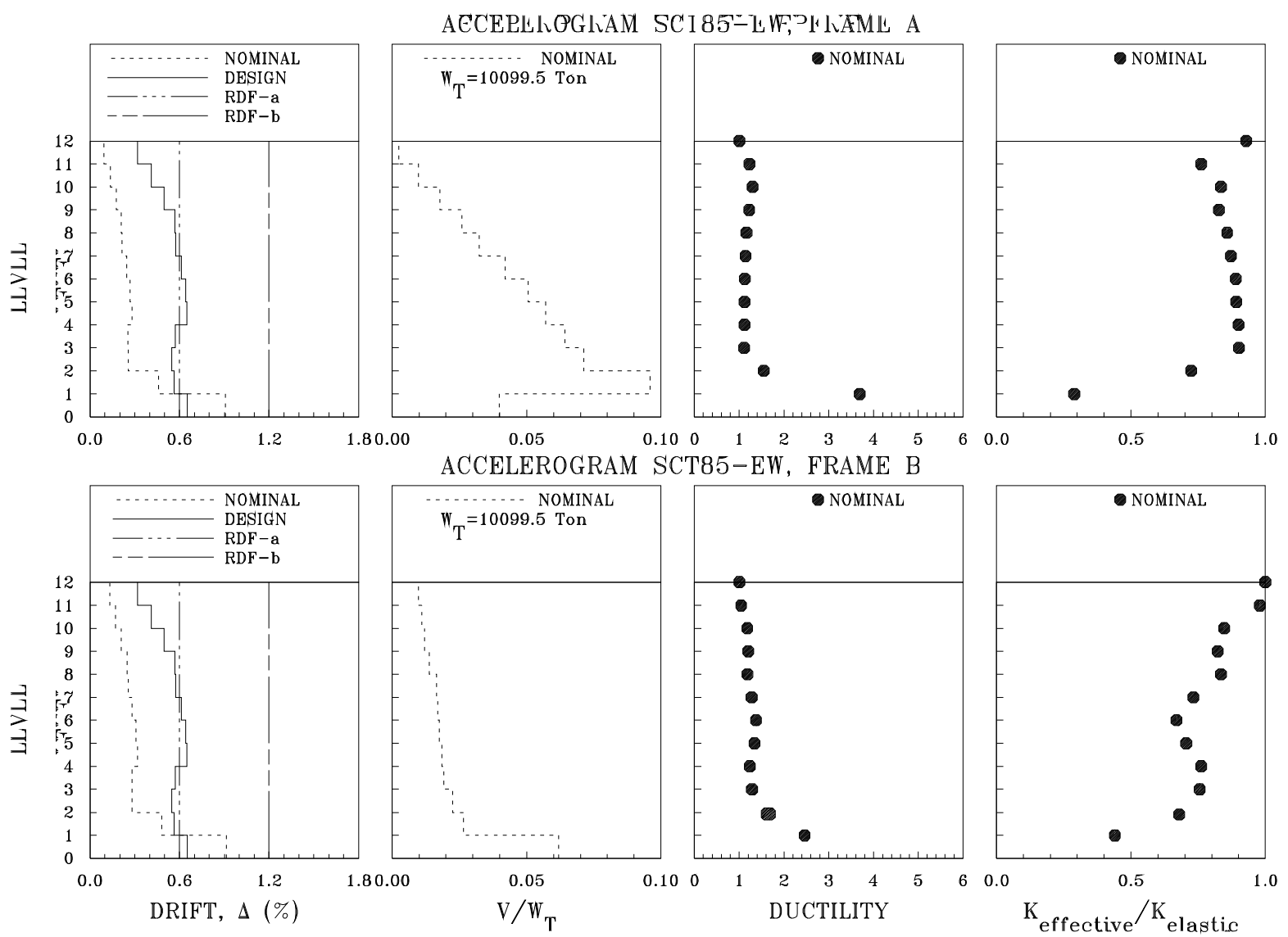

Fig. (8). Peak response envelopes for frames A and B of model ED100Q32. 

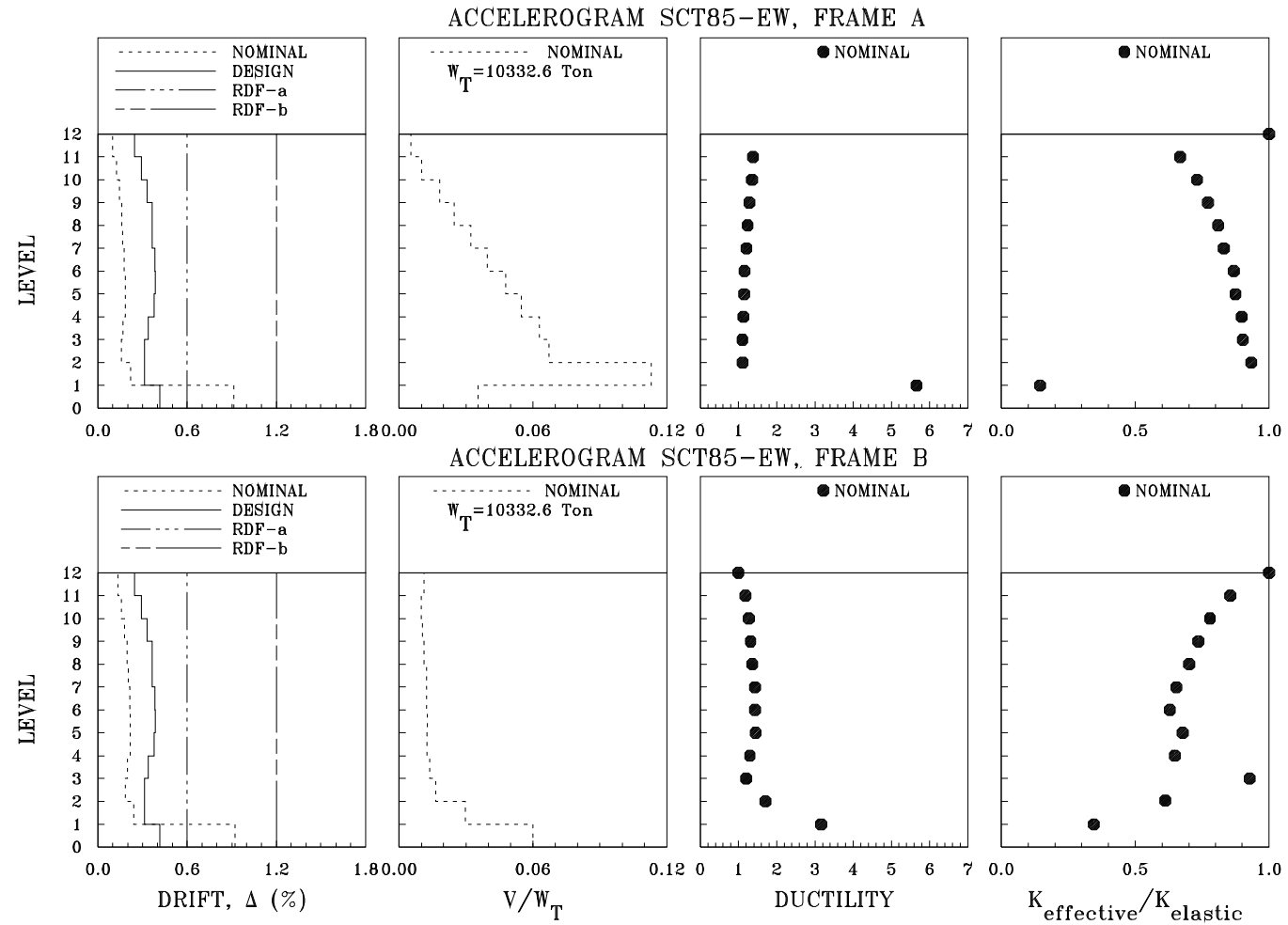

Fig. (9). Peak response envelopes for frames A and B of model ED100Q4.
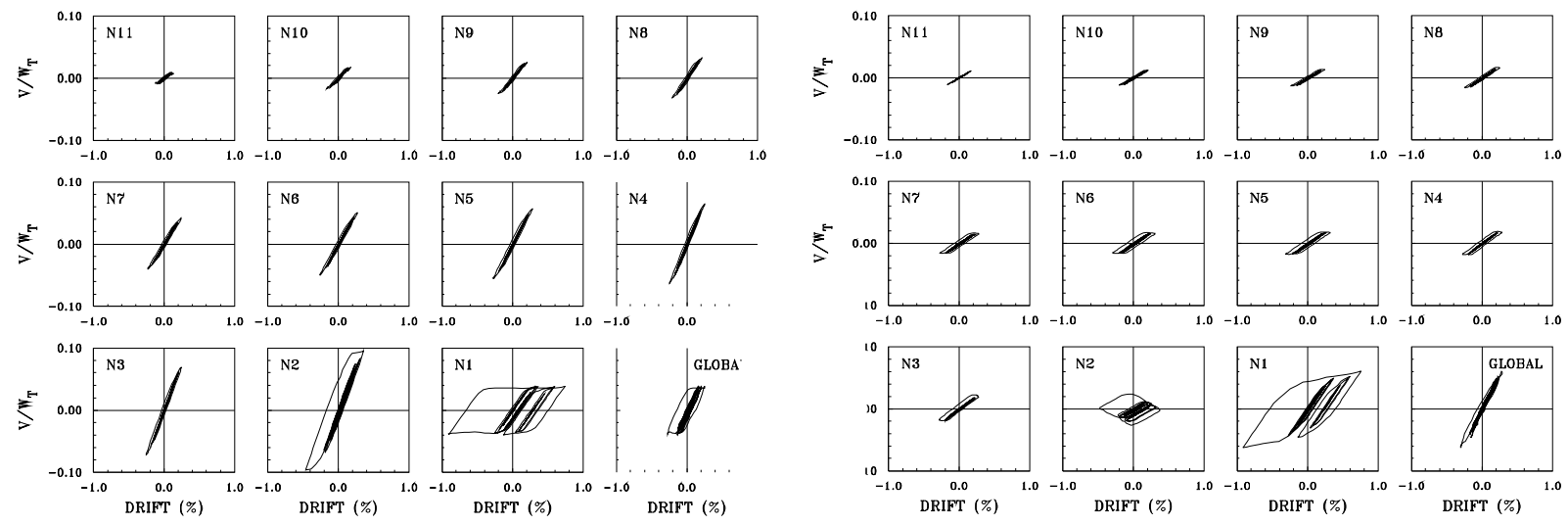

a) Frame $\mathrm{A}$
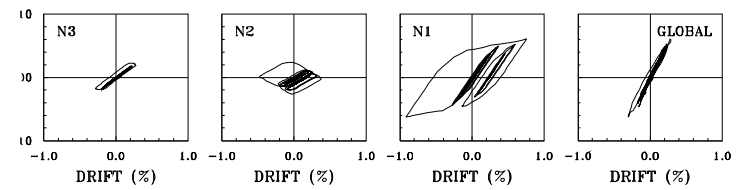

b) Frame B

Fig. (10). Hysteresis curves for model M100Q32 under SCT-
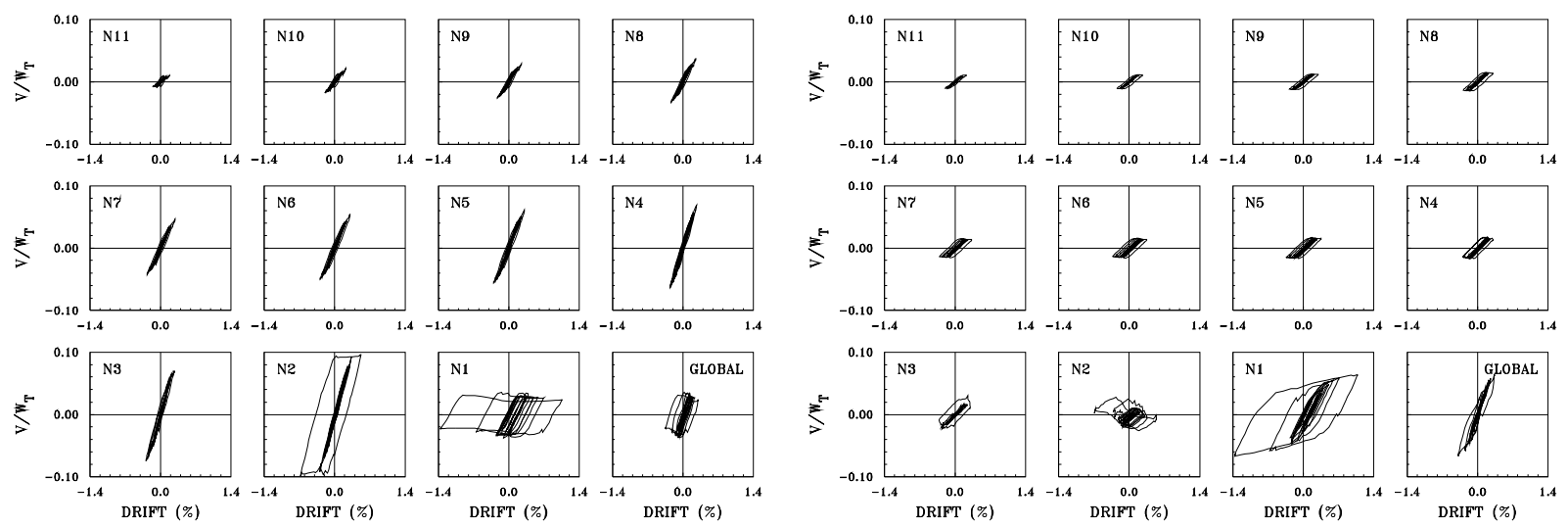

a) Frame $\mathrm{A}$
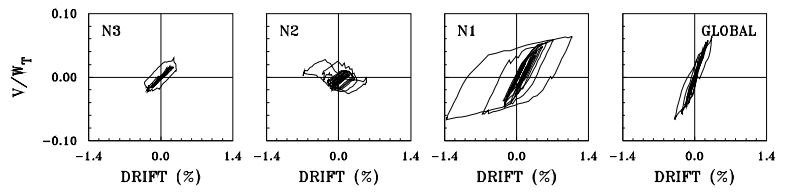

b) Frame B

Fig. (11). Hysteresis curves for model M100Q4 under SCT-EW acceleration record. 

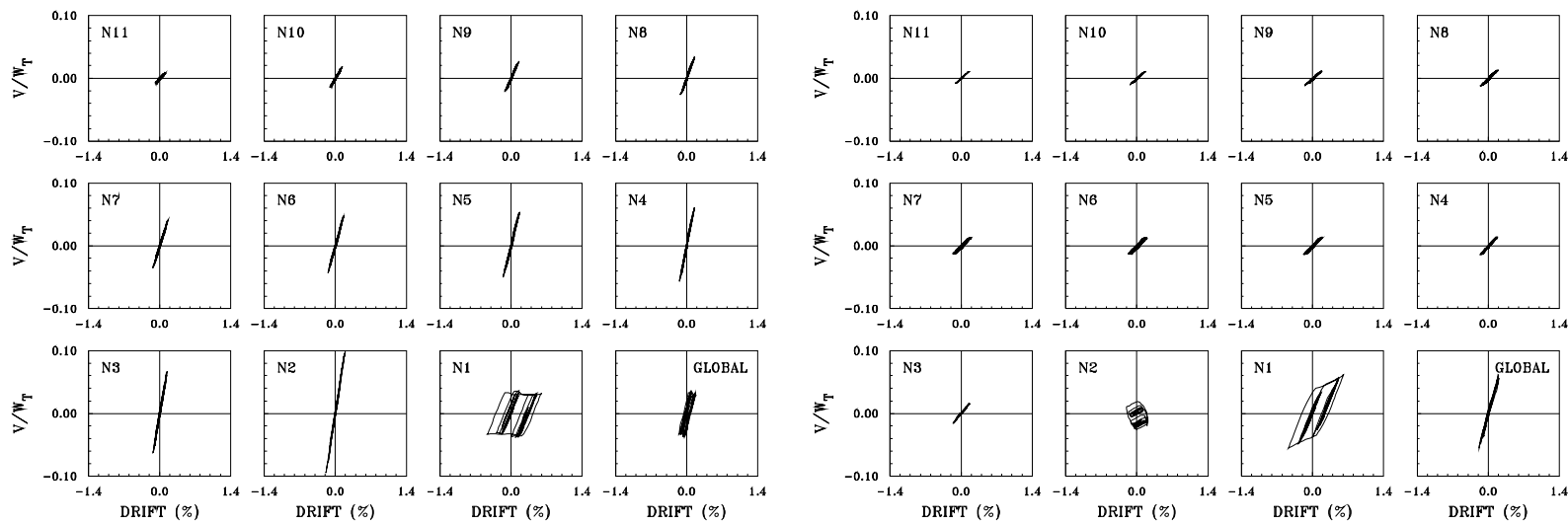

a) Frame A
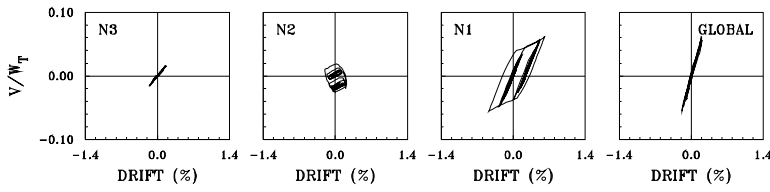

b) Frame B

Fig. (12). Hysteresis curves for model ED100Q32 under SCT-EW acceleration record.
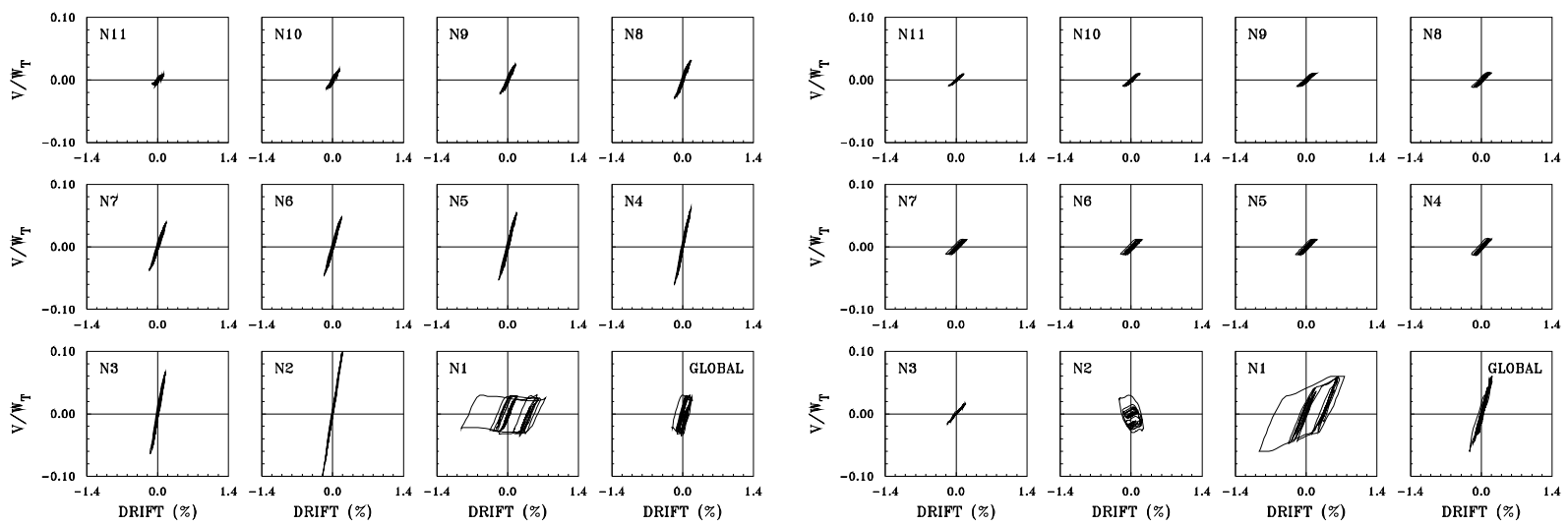

a) Frame $A$
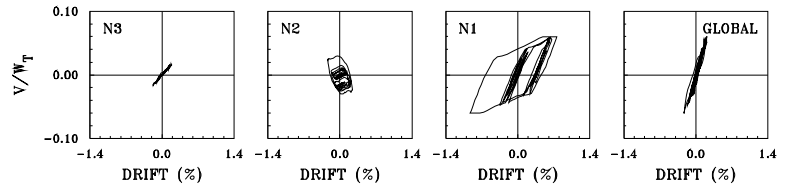

b) Frame B

Fig. (13). Hysteresis curves for model ED100Q4 under SCT-EW acceleration record.
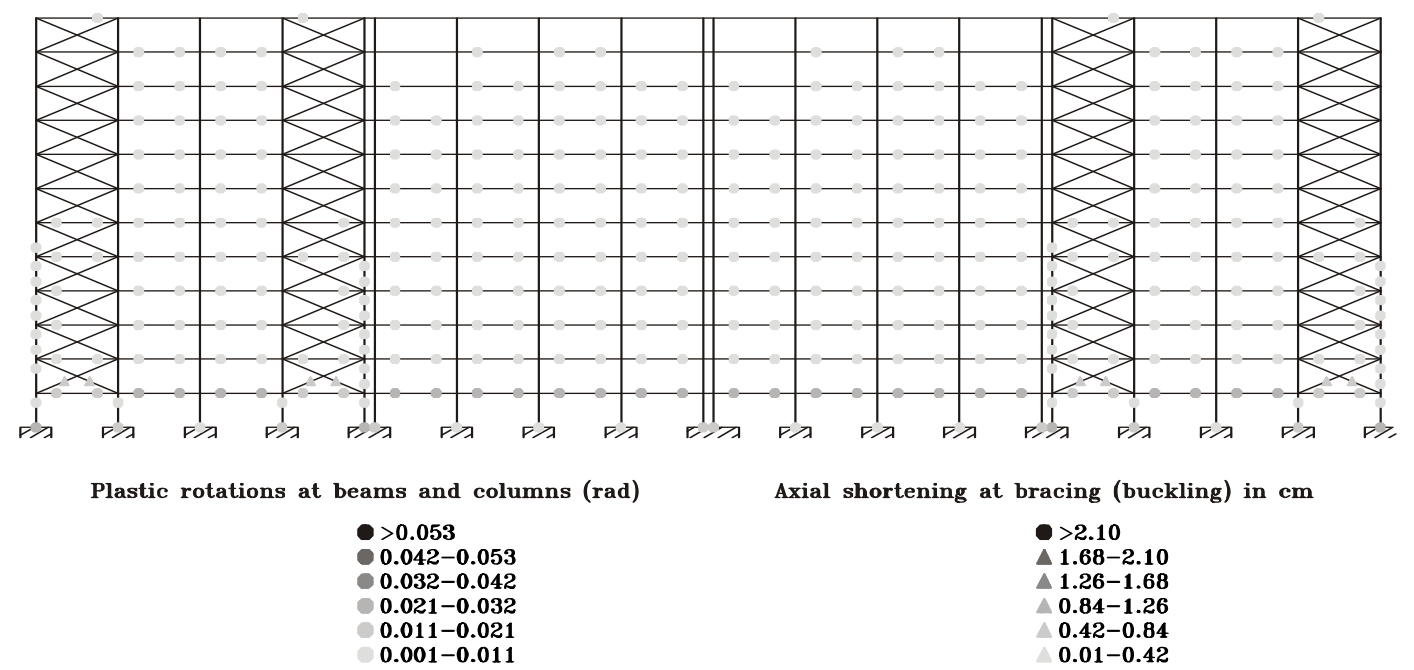

Axial shortening at bracing (buckling) in $\mathrm{cm}$

Fig. (14). Yielding mapping envelope, M100Q32 model. 


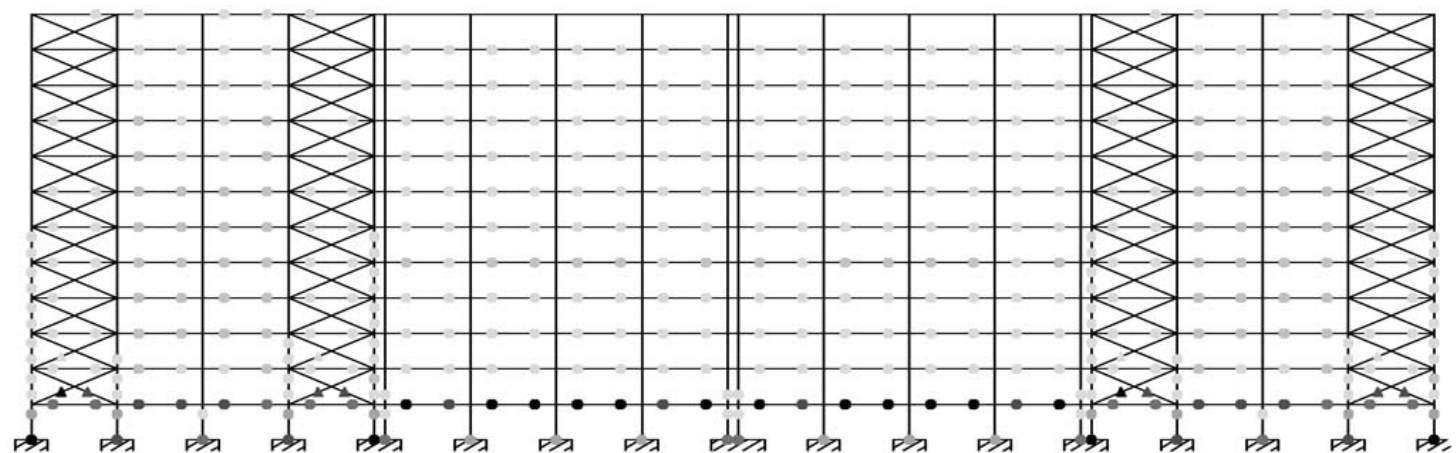

Plastic rotations at beams and columns (rad)

- $>\mathbf{0 . 0 5 3}$

0.042-0.053

0.032-0.042

0.021-0.032

$0.011-0.021$

0.001-0.011

Axial shortening at bracing (buckling) in cm

- $>2.10$

$\triangle 1.68-2.10$

$\Delta$ 1.26-1.68

0.84-1.26

$0.42-0.84$

Fig. (15). Yielding mapping envelope, M100Q4 model.

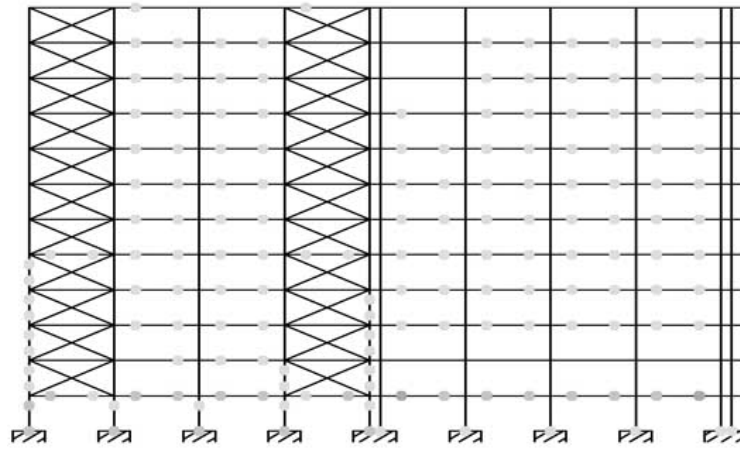

Plastic rotations at beams and columns (rad)

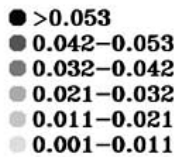

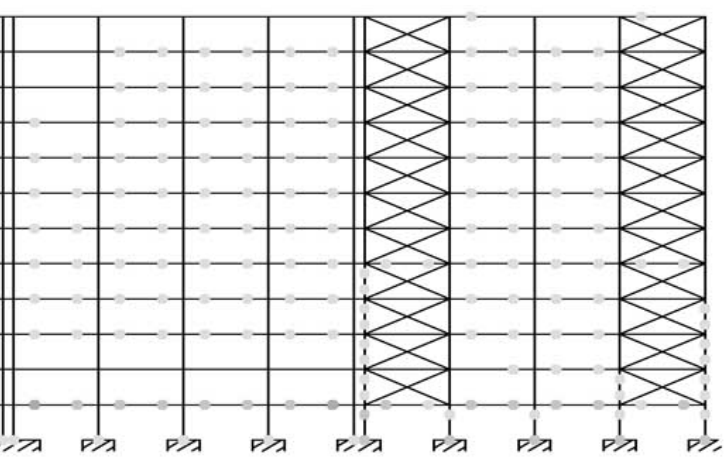

Axial shortening at bracing (buckling) in $\mathrm{cm}$

- $>2.10$

$\Delta$ 1.68-2.10

$1.26-1.68$

0.84-1.26

$0.42-0.84$

$0.01-0.42$

Fig. (16). Yielding mapping envelope, ED100Q32 model.

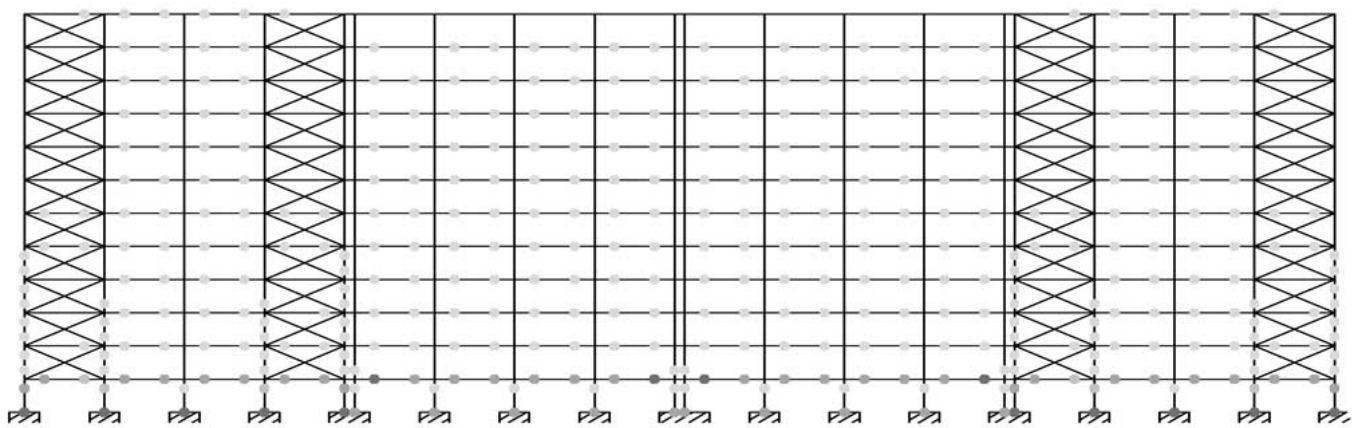

Plastic rotations at beams and columns (rad)

- $>0.053$

$0.042-0.053$

$0.032-0.042$

$0.021-0.032$

$0.011-0.021$

0.001-0.011
Fig. (17). Yielding mapping envelope, ED100Q4 model.

(4) A new finding of this study, perhaps the first one to model the interaction among frames of buildings with a
Axial shortening at bracing (buckling) in cm

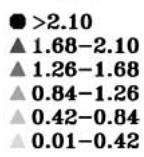

suspected soft first story in a given direction, is to visualize how the deficit in the shear capacity of the first story 
of the perimeter frames has to be taken by the interior (regular) frames (represented by frame B). The interior frames (frame B) experience higher shear forces, ductility demands and develop smaller peak-to-peak lateral shear stiffnesses not only in the first story, but also in the second story (Table 6, Figs. 6 to 9).

(5) Perhaps the most important finding about the interaction among frames in the longitudinal direction of interest can be addressed from the observation of the hysteresis curves of Figs. (10) to (13), which depict the details of how the buildings try to compensate the discontinuity of the perimeter frames in the first story. It can be observed for example, for model M100Q32 (Fig. 10) that, in the nonlinear range of response, the discontinuity of perimeter frames (A) forces interior frames (B) to work in the opposite direction in the second story (level N2), in order to compensate for the deficit of shear strength of the building in the first story. Not only the interior frames are subjected to this inversion of forces in the second story, but their story shear and inelastic deformation are increased in this story. When these incremented shear forces and lateral deformations in the second story are relatively large in the interior frames (model M100Q4, Fig. 11), they can trigger the yielding of columns in the interior frames at that story (Fig. 15). In addition, the story shear and inelastic deformation of interior frames are also substantially increased in the first story. This behavior was observed for all models (Figs 10 to 17). It is worth noting that the described behavior cannot be detected using elastic analyses, as: (a) it was not anticipated in the design process using ETABS software and, (b) it was not observed in the DRAIN-2DX analyses for the models depicted in Fig. (5) when other considered acceleration records drove the models to an elastic response.

(6) As it was expected, yielding mappings (Figs. 14 to 17) depict an important number of column yielding in the soft first story for perimeter frames and, in some cases, one can observe the buckling of the braces of the second story, particularly for models M100Q32 and M100Q4 (Figs. 14 and 15) that have slender braces in the second story $(k L / r=89.2)$. For models ED100Q32 and ED100Q4, where the braces in the second story have a slenderness ratio $k L / r=64.0$, all braces remain elastic (Figs. 16 and 17). For the models that were not affected by the 0.8 reduction factor in $Q^{\prime}$ (M100Q4 and ED100Q4, Figs. 15 and 17), the yielding of the first story columns and some columns from stories 2 to 6 of the perimeter frames was more important than for those models designed with the 0.8 reduction factor in Q' (M100Q32 and ED100Q32, Figs. 14 and 16). In general, the column yielding of interior frames is reduced to the first two stories for all models (Figs. 14 and 17). It can also be observed from Figs. 14 to 17 that the amount of beam yielding is consistent with the weak-beam, strong-column design philosophy implicit in the seismic design of SMRFs according to the guidelines of NTCS-95. However, this condition is severely affected by the discontinuity of the braces of the perimeter frames at the first story, leading to a soft-story yielding mechanism of the perimeter frames in all models. In fact, it can also be observed from the yielding mappings that, in general, the models designed as irregular buildings (M100Q32 and ED100Q32, Figs. 14 and 16) have an improved mapping with respect to their counterpart buildings designed as regular buildings (M100Q4 and ED100Q4, Figs. 15 and 17). This is important, as it seems that the simple recommendation of Mexican codes of increasing the design strength to improve the seismic behavior of buildings with soft story irregularity is somewhat effective. Some engineers would consider that the relevant question is not whether buildings designed as irregular according to Mexican codes perform better than those designed as regular ones, but if the response of buildings designed as regular is acceptable or not. On this regard, it is worth noting that an acceptable seismic responses have been obtained and reported for regular RC-SMRFs buildings with similar configuration and that were designed according to the same code [12]. The referred buildings were designed as regular structures and the amount of beam yielding obtained is consistent with the weak beam - strong column design philosophy assumed in the code [12]. Therefore, as the global design strategy for regular SMRFs building is effective, it is also relevant to highlight that the simple design strategy specified in Mexican codes for soft/weak story irregularity seems to be practical and effective.

(7) It can be observed from the peak dynamic normalized story shear forces obtained for the building models under study (Table 12) that the first soft-story irregularity condition due to strength (weak story) is better defined by the soft-story frame concept proposed by the author (in terms of the shear strength ratio $V_{2 m} / V_{1 m}$ ) rather than the all-frames definition of NTCS-95 (in terms of the shear strength ratio $V_{2} / V_{1}$ ), if the proposed limiting values of 2.0 (NTCS-95) or 1.5 (NTCS-2004) are considered. The results presented in peak response envelopes, hysteresis curves and yielding mappings show that a first soft-story condition is developed in all models. However, according to the results reported in Table 12, a soft-story condition due to strength "is not likely" according to NTCS-95, as $V_{2} / V_{1}<2.0$.

\section{CONCLUDING REMARKS}

Taking into account the nonlinear dynamic analyses of the reference models, one can arrive to the following observations regarding the first soft story condition, granted the limitation of this research that only few (but detailed) models designed to fulfill all the requirements of MFDC were studied.

It would be convenient that building codes would specify in their commentaries which method of analysis (shear modeling or flexural modeling) should be used in order to compute the lateral story stiffness of buildings when assessing the likeliness of a soft story irregularity condition. In this paper it has been shown that, for a specific building, one can arrive to different answers depending on the method of analysis that was used. Also, this observation can be extended to the assessment of the shear strength capacity to decide on the likeliness of a weak story irregularity condition. 
All studied building models develop a first soft story response when subjected to acceleration records associated to the design spectrum of NTCS-95. In addition, the models that were not designed as irregular buildings (M100Q4 and ED100Q4) experienced a more severe nonlinear, soft first story response than those models designed as irregular buildings (M100Q32 and ED100Q32). Therefore, it seems that the simple recommendation of Mexican codes to improve the seismic behavior of buildings with soft story irregularity is somewhat effective. In contrast, according to NTCS-95, M100Q4 model should not be designed as an irregular building; nevertheless, the building developed a strong soft story response. However, with the current definition of NTCS2004, this model should now be designed as an irregular building (Table 3), as the new limit proposed in NTCS-2004 takes into account, among other studies, the ones that are reported in this paper.

The results of this study lead to support the proposal of the author that perhaps the definition of the soft first story irregularity condition in Mexican codes, and other seismic codes worldwide, should be reviewed. The proposal of the author is that the soft first story irregularity condition should be defined as a substantial reduction of the lateral shear stiffness of one or more resisting frames within a given story, instead of as a significant reduction of the lateral shear stiffness of all resisting frames within a given story, as established in Mexican codes. Finally, future works must also be directed to assess if the additional modifications included in NTCS-2004 allow the designer to arrive to safer designs for buildings with a soft first story condition.

\section{ACKNOWLEDGMENTS}

Financial support of Secretaría General de Obras del Gobierno del Distrito Federal, Mexico City, Mexico is acknowledged. Prof. Enrique Del Valle is thanked for his critical review of the original research and manuscript.

\section{REFERENCES}

[1] A. Tena-Colunga, "International seismic zone tabulation proposed by the 1997 UBC code: Observations for Mexico", Earthquake Spectra, vol. 15, no. 2, pp. 331-360, 1999.

[2] NTCS-95, "Normas Técnicas Complementarias para Diseño por Sismo", Gaceta Oficial del Departamento del Distrito Federal, February 1995 (in Spanish).

[3] NTCS-04, "Normas Técnicas Complementarias para Diseño por Sismo", Gaceta Oficial del Distrito Federal, October 2004 (in Spanish).

[4] UBC-97, "Uniform Building Code, volume 2 - structural engineering design", International Conference of Building Officials, Whittier: California, 1997.

[5] ASCE 7-05, "Minimum design loads for buildings and other structures", ASCE Standard ASCE/SEI 7-05, American Society of Civil Engineers, ISBN 0-7844-0809-2, 2005.

[6] IBC-2006, "International Building Code, 2000 to 2006 Editions", International Code Council-ICC Inc. 2006.

[7] A. Tena-Colunga, "Reflexiones sobre la definición y evaluación de la condición de irregularidad por piso suave de acuerdo con lo establecido por las NTCS-95 del RCDF-93," in XII Congreso Nacional de Ingeniería Estructural, León, Mexico, November 2000, CDROM (in Spanish).

[8] A. Tena-Colunga, "Evaluación sísmica de la condición de irregularidad por piso suave de estructuras mixtas diseñadas conforme al RCDF-93," in XIII Congreso Nacional de Ingeniería Sísmica, Guadalajara, Mexico, November 2001, CDROM (in Spanish)

[9] S. E. Ruiz and R. Diederich, "The Mexico earthquake of September 19, 1985 -The seismic performance of buildings with weak first story", Earthquake Spectra, vol. 5, no. 1, pp. 89-102, 1989.

[10] L. Esteva, "Nonlinear seismic response of soft-first-story buildings subjected to narrow-band accelerograms", Earthquake Spectra, vol 8, no. 3, pp. 373-390, 1992.

[11] E. Rosenblueth, M. Ordaz, F. J. Sánchez-Sesma and S. K. Singh, "The Mexico earthquake of September 19, 1985-Design spectra for Mexico's Federal District", Earthquake Spectra, vol. 5, no. 1, pp. 273-291, 1989.

[12] A. Tena-Colunga, H. Correa-Arizmendi, J. L. Luna-Arroyo and G. Gatica-Avilés, "Seismic behavior of code-designed medium rise special moment-resisting frame RC buildings in soft soils of Mexico City", Eng. Struct., vol. 30, no. 12, pp. 3681-3707, 2008.

This is an open access article licensed under the terms of the Creative Commons Attribution Non-Commercial License (http://creativecommons.org/licenses/by-nc/3.0/) which permits unrestricted, non-commercial use, distribution and reproduction in any medium, provided the work is properly cited. 